\title{
Students' Use of Smartphones at a Historically Disadvantaged University
}

\author{
Sello Mokoena \\ Rembrandt Klopper \\ Sam Lubbe
}

\section{Abstract}

As technology becomes cheaper the potential for learning is greater, preparing and disseminating learning material through smartphones is likely to become popular. However, it was not clear whether students from the most disadvantaged backgrounds, have the right equipment (smartphones) to support learning at a historically disadvantaged university. This study assesses smartphone ownership as a potential tool for enhancing students' learning at a relatively resource-poor higher education (HE) environment in rural KwaZuluNatal. Correspondence universities, such as 'Unisa' and examples worldwide in HE, use students' smartphones for educational purposes. Primary data were collected from postgraduates and undergraduate students using a selfadministered structured questionnaire for all faculties. The unified theory of acceptance and use of technology (UTAUT) was employed to account for students' perceived ease of use (EOU) and perceived usefulness (PU). The results revealed smartphone ownership and use was greater than the ownership and use of regular cellular phones. Regular cellular phone users commented on smartphone capabilities as enhancing learning.

Keywords: Smartphones, socio-economic status, learning, unified theory of acceptance use of technology, consumer perceived values, access, M-learning, ease of use, perceived usefulness, HE, Information Technology (IT).

\section{Introduction}

The changing world of mobile telecommunication is driven by smartphone 
availability and potential in each and every industry. The use of smartphones as a learning tool is inevitable, and the availability of these devices must be facilitated at HE institutions (Yu \& Conway 2012:831). For improvement of communication channels, information search and business daily updates on the move, the smartphone is the imperative tool for use. Since smartphones have been identified as potential tools for gathering and disseminating information, the new path to grow their use is in education (Mokoena 2013). Smartphone popularity is increasing among the general public at an even ever faster pace (Samar \& Soomro 2013:216).

Today users are caught in distracted smartphone societies in hospitals, shopping malls, educational institutions and public places because of its ubiquitous nature. Smartphones as potential tools (Woodcock, Middleton \& Nortcliffe 2012:2) incorporate computing capabilities: their functionality comprises recorders, cameras, web browsing, media production, social media, full QWERTY keyboards, communication and entertainment, complemented by a range of applications (apps) that are installed through downloads.

Mobile learning through the use of smartphone developments and new capabilities has changed the academic environment of students at universities and colleges (Yu \& Conway 2012). This has raised a question: to what extent are access and ownership of smartphones prevalent at an HDU as a potential tool to enhance students' learning? Many studies (El-Hussein \& Cronje 2010; Woodcock et al. 2012; Yu \& Conway 2012; Bakon \& Hassan 2013) have investigated the use of smartphones by students at HE institutions, including distance learning universities and resource-rich HE institutions in both developing and developed countries. There has been little attention to residential universities as to whether the right tools are available to enhance students' learning. This paper investigates the use and ownership of smartphones among university students from the lower socio-economic backgrounds, and whether they have the right tool to enhance their learning at a poorly resourced $\mathrm{HE}$ institution.

The use of smartphones will increase students' engagement with and commitment to their learning activities (Clough, Jones, McAndrew \& Scanlon 2007:368). The literature reviewed showed a possibility that smartphone availability and potential supports the use of the device as a learning tool in HE (Yu \& Conway 2012:831).

This paper is structured as follows; the researchers draw the literature from the peer-reviewed article on technology acceptance and use of the UTAUT 
model by Venkatesh, Morris, Davis and Davis (2003:425) to form the theoretical framework of the investigation. They then employed the research methodology that provided the investigation with the required data. The findings supported the desirability of smartphones being available in an HDU as a potential tool to enhance students' learning. Then conclude with discussions and recommendations for future research.

\section{Literature Review and Theoretical Background}

In defining the smartphone, the study considers what makes the smartphone 'smart'. Yu and Conway (2012:832) notice the smart features in the device that allows the user to search and access information anytime, anywhere. According to Varkasalo, Lopez-Nicolas, Molina Castillo and Bouwman (2010:242) the smartphone enables the user to install and use the applications on their own, based on their own interest and need. The user downloads applications (apps) to boost his or her performance level. That is the smart act of the smartphone. Customising the device according to the owner's needs and the constant connectivity to the internet makes it smarter. Caverly, Ward and Caverly (2009:38) note that with the $3 \mathrm{G}$ internet-capable mobile phones, there are over 60000 apps for $3 \mathrm{G}$ mobile phones.

These apps can be part of educational development. The use of smartphones is gradually increasing and diversified across different sectors of education in both developed and developing countries (Ally 2009:10). At the University of Central Arkansas smartphones have changed students' lives and behaviour due owing to its universal acceptance and powerful functionality (Yu \& Conway 2012:832). At the University of Bath in England students recommend the texting service as a powerful reminder for engagement in their daily activities (Jones \& Edwards 2009:7). HE students in Malaysia (Bakon \& Hassan 2013:3) indicate that social values, including the overall customer perceived value (CPV) associated with the smartphone, have a profound effect on students' academic performance, and that effect has spread across students who differ in behaviour and academic performance levels.

The perceived values of the smartphone have changed students' perception about the device, their behaviour, and their academic performance levels because of its capabilities (Mokoena 2013). For developing countries the constant availability of the Internet on smartphones has compensated for the limitations on internet access. Owing to the lack of ICT infrastructure in certain 
areas of Africa, the existing telecommunications cannot reach the bulk of the population. Therefore African countries are experiencing more growth in wireless infrastructure and wireless devices than first world countries (Barker, Krul, \& Mallinson 2005:20). The high speed of Internet connectivity is part of students' means of access to information related to his/her studies. Bruner and Kumar (2005:553), in explaining the consumer acceptance of handheld internet devices, note that their perceived usefulness contributes to consumer adoption of the Internet service of handheld devices.

This mobile browsing connectivity increases the availability and growth of the smartphone in developing countries, villages and HE institutions (Yu \& Conway 2012:835). Today, mobile phones are playing a role as a mechanism for delivering distance learning between students and the university. UNISA prefers SMS communication by smartphone to facilitate distance learning in that the message goes directly to the intended student (Nonyongo, Mabusela, \& Monene 2005:1). Sarwar and Soomro's (2013:218) study discloses key positive and negative impacts of smartphone use and its availability on society at large.

According to Lunden (2014:1) on the device forecast for the world of communications and technology indicates that mobile-wireless technology is increasing fast. The worldwide combined shipment of technology and communication devices amounts to 2.5 billion PCs, tablets and mobile handsets. Of those devices, probably 1.9 billion are mobile handsets; 1.1 billion which use the Android Operating System. This has indicated the growth of smartphone ownership has overtaken that of PCs, which had dominated the market before. Yu and Conway (2012:831) note the evolution of smartphones and lists literature on the device in the settings of higher education that reveal it as a powerful tool for students' learning.

Attewell and Savill-Smith (2005:3) refer to mobile learning as the process of pocketing and using smartphones and cellular phones by students wherever and whenever to be able to receive unbroken transmission signals. This is one of the challenges in developing countries (Islam \& Gronlund 2011:6).

\section{Theoretical Background - UTAUT Conceptual Research Model}

Several models are used to investigate new technology adoption in IT. The 
UTAUT by Venkatesh et al. (2003) uses eight theories in their varied training which are: the theory of reasoned action (TRA), the technology acceptance model (TAM), the theory of planned behaviour (TPB), combined TAM and TPB, the diffusion of innovation theory (DIT), the social cognitive theory (SCT), the motivational model (MM), and the model of Personal Computer use (MPCU). The UTAUT serves as a baseline model, and has been applied to the study of a variety of technologies in both organisational and non-organisational settings (Venkatesh, Thong \& Xu 2012:157).

These eight theories have different ideas and principles, and were mixed to reach a combined view of user acceptance of IT (Abdulwahab \& Dahalin 2010:268). The first theory integrated in the UTAUT is the TRA (Fishbein \& Ajzen 1975) that explains the links between the beliefs, attitudes, intentions, norms and behaviour of individuals. Behavioural Intention (BI) determines personal behaviour to perform interaction, and itself is determined by the person's subjective norms and attitude towards the behaviour. TAM deals with the predictions of acceptability of an information system or a tool. This model suggests that the acceptability of an information system is determined by two main factors: perceived usefulness and ease of use).

The TPB (Ajzen 1991:182) results from the limitations on behaviour over which people have little control. This theory focuses on perceived behavioural intention, which refers to readily available resources, skills and opportunities, as well as the person's own perception of the importance of achieving results. Combined TAM and TBP (Taylor \& Todd 1995:145) is the combination of theory predictors of the TAM and TPB that both perceived usefulness positively influences attitudes on subjective norms, and perceived behavioural control positively influences usage behaviour. DIT is the theory of how, why and at what pace new ideas and technology grow across cultures, operating at both an individual and organizational level (Oliveira \& Martins 2011:111).

The SCT (Bandura 1986) is about self-efficacy as a key self-discipline, which refers to the judgment of one's ability to use technology to accomplish a particular task. Behaviour, environment, personal attitude and motivation influence individual behaviour. MM states that the behavioural intention of using new technology is affected by internal motivation and external motivation. Internal motivation refers to the enjoyment of using the Information System (IS), and external motivation refers to the perceived usefulness of the IS (Davis, Bogozzi \& Warshaw 1992). 
Lastly, the MPCU covers factors affecting the use of a new technology system, including perceived consequences affecting social factors and facilitating conditions. The perceived result of MPCU covers complexity, job fitness and long-term consequences (Thompson, Higgins \& Howell 1991).

\section{The UTAUT Model Variables}

These variables indicated by the UTAUT were reviewed and presented to determine the behavioural intention (BI) on the use and ownership of the smartphone by students (Venkatesh et al. 2003).

\section{Performance Expectancy}

According to Wang, Wu and Wang (2009:95) five constructs are suggested from the existing model to capture the concept of performance expectancy. Which are perceived usefulness (TAM and C-TAM-TPB), internal motivation (MM), and job fit (MPCU), relative advantage (DIT), and outcome expectations (SCT). Performance expectancy is the level of an individual user who believes that using the smartphone for learning will help in enhancing his/her performance (Abdulwahab \& Dahalin 2010:269).This building part of the UTAUT was reported as more important in all measurements despite environmental settings.

\section{Effort Expectancy}

Three constructs from different models relate to effort expectancy: perceived ease of use (TAM), complexity (MPCU), and ease of use (IDT). The critical determinant of behavioural intention in the early stages of mobile learning is effort expectancy (Wu, Tao \& Yang 2008:921).

\section{The Influence of Rural Socio-Economic Measures}

Socio-economic measures representing a developing country are the wealth, income, expenditure, education and housing conditions (Doocy \& Burnham 2005:2). Social and economic influences are key in shaping one's use of new 
technologies. Three constructs from the models capture the concept of social factors: subjective norms (TRA, TPB and C-TAM-TPB), socio-economic status (MPCU), and image (DIT) (Wu et al. 2008:930). The perception is that the individual user believes that $\mathrm{s} / \mathrm{he}$ should use smartphone technology for learning, and it is important. The social influence construct has the most facts and ideas from six theories/models used (Abdulwahab \& Dahalin 2010: 269).

\section{Self-Management for Learning}

This is the degree to which an individual feels s/he is self-disciplined, and can engage in autonomous learning using the smartphone devices. Since mobile learning is defined as learning using the mobile devices, it is expected that a person's level of learning using the smartphone will have a positive impact on his/her behavioural intention on self-management for learning through mobile learning (Wang et al. 2009:100).

\section{Behavioural Intention}

The behavioural construct has a direct impact upon the individual's actual use of technology. This construct originates from the TRA. The technology acceptance model is the key standard in user acceptance research owing to its importance in information management, so behavioural intention is introduced to the Management Information System (MIS) through the TAM (Abdulwahab \& Dahalin 2010:270).

\section{User Acceptance}

In this study the ownership and use of the smartphone as a potential tool for students' learning was used as the indicator of user acceptance, as it is quite a challenge to have data about the actual usage (Abdulwahab \& Dahalin 2010:271). In undertaking the theory of market research and the theory of consumer behaviour about smartphone use as a potential tool in HE institutions, new opportunities are spotted in supporting students' learning environments, processes and activities on campus (Lamb, Hair, McDaniel, Boshoff \& Terblanche 2008). 
Students' Use of Smartphones at a Historically Disadvantaged University

\section{Research Questions}

- How has smartphone use affected students' way of learning at an HDU?

- What access to smartphones do students at an HDU have?

- What smartphone capability or function enhances students' learning at an HDU?

- How do students' use a smartphone with functionalities to make learning enhancement feasible at an HDU?

- How many students' at an HDU possess a smartphone to enhance their learning?

\section{Methodology}

The study is a descriptive study observing a subset of students from poor socioeconomic backgrounds at an HE institution. It targeted postgraduate and undergraduate students from all faculties at HDU. The HDU is one of South Africa's so-called 'historically disadvantaged universities', located in a remote rural area of KZN, with a number of students, most of whom are from least advantaged backgrounds with low socio-economic status. A cross-sectional research design was conducted by assessing variables of interest in a sample once, and applying the results of to the population. Quantitative method was used. Quantitative researchers seek statistical perceptions, the collection of facts, and relationship of one set of facts to another (Bell 1999).

The investigation focused on the use and ownership of the smartphone at an HDU as a potential tool to enhance students' learning. Geographical parameters were strictly limited to students from the main campus four faculties: Education; Commerce, Administration and Law; Science and Agriculture; and Arts. A stratified random sampling method was used. The study sample was divided into strata of postgraduates and undergraduates from all faculties. Table 1 represents the population from which the sample size was drawn. Table 2 represents the sample size of the investigation. 386 students were taken from the population of 14687 as study respondents. 
Sello Mokoena, Rembrandt Klopper \& Sam Lubbe

\section{Study Context and Sample}

Table 1: Student Population at an HDU (2010)

\begin{tabular}{|c|c|c|c|}
\hline Faculty & $\begin{array}{l}\text { Postgraduate } \\
\text { Students }\end{array}$ & $\begin{array}{l}\text { Undergraduat } \\
\text { e Students }\end{array}$ & Total \\
\hline 1. Arts & 425 & 4112 & 4537 \\
\hline 2. Education & 323 & 5103 & 5426 \\
\hline $\begin{array}{l}\text { 3. Commerce, } \\
\text { Administration } \\
\text { and Law }\end{array}$ & 75 & 2771 & 2846 \\
\hline $\begin{array}{l}\text { 4. Science and } \\
\text { Agriculture }\end{array}$ & 337 & 1541 & 1878 \\
\hline Total & 1160 & 13527 & 14687 \\
\hline
\end{tabular}

Source: HDU website (2010).

A 95\% confidence level was used, which resulted in a risk estimate of 5\%. At $95 \%$, the response distribution is $50 \%$. The formula to calculate the sample size is:

$\mathrm{n}=\mathrm{x}^{2} \mathrm{NP}(1-\mathrm{P}) / \mathrm{d}^{2}(\mathrm{~N}-1)+\mathrm{x}^{2} \mathrm{P}(1-\mathrm{P})($ Krejcie \& Morgan 1970)

$\mathrm{n}=$ required sample size

$\mathrm{x}^{2}=$ the table value for 1 degree of freedom at the desired confidence level

$\mathrm{N}=$ the population size

$\mathrm{P}=$ the population proportion (assumed to be 0.50 since this provides the maximum sample size)

$\mathrm{d}^{2}=$ the degree of accuracy expressed as a proportion of 0.05 (Krejcie \& Morgan 1970). 
Students' Use of Smartphones at a Historically Disadvantaged University

Table 2: Sample Size

\begin{tabular}{|c|l|l|l|}
\hline Faculty & $\begin{array}{l}\text { Postgraduate } \\
\text { Students }\end{array}$ & $\begin{array}{l}\text { Undergraduate } \\
\text { Students }\end{array}$ & Total \\
\hline 1. Arts & 11 & 108 & 119 \\
\hline 2. Education & 8 & 134 & 142 \\
\hline $\begin{array}{l}\text { 3. } \begin{array}{l}\text { Admmerce, } \\
\text { and Lawistration }\end{array} \\
\begin{array}{l}\text { 4. Science and } \\
\text { Agriculture }\end{array}\end{array}$ & 2 & 73 & 75 \\
\hline Total & 30 & 41 & 50 \\
\hline
\end{tabular}

\section{Data Collection}

Secondary data was collected by means of a literature search, and examining theories underpinning the UTAUT model. They provided the investigation on how smartphone use has changed students' behaviour and performance levels. The literature searched was focused on how students at HE institutions view the use of smartphones. The literature revealed that students' viewed the smartphone as a potential tool to enhance their learning irrespective of the location of the institution (Yu \& Conway 2012:832).

A structured questionnaire with closed-ended questions was used to collect data from the participants of the study. Each participant was asked the same questions. The questionnaires used had three sections, requesting data on biographical information, students' opinions and experience on smartphones as a potential tool to enhance their learning. The questionnaire was distributed to all faculties and was distributed to the respondents from $08 \mathrm{~h} 00$ to $16 \mathrm{~h} 00$ for a period of two weeks.

\section{Data Analysis Techniques}

Data collected was quantitative in nature, summarised in tables. SPSS package was used for calculating and analysing descriptive statistics. According to 
Babbie (1992), the binomial test is an exact test of statistical significance of deviations from a theoretically expected distribution of observations into two categories. This test was used to determine whether there is a significant difference between the number of smartphone users and regular cellular phone users.

The following definition was noted when interpreting the results of the statistical analysis since large sample statistics have relatively small variances: Statistical significance is concerned with whether a research result is due to chance or sampling variability; practical significance is concerned with whether the result is useful in the real world (Kirk 1996:5).

\section{Findings}

Data collected from the respondents' biographical information were used for classification such as gender and the mobile phone type. Data were reported through tables. The Table 3 question was answered by 386 respondents. Of the 385 respondents, $195(50.6 \%)$ were male and 190 (49.4\%) were female. Wang et al. (2009:102) use gender and age as determinants to investigate the acceptance and adoption of mobile learning. Compare the study on by Nonyongo et al. (2005) at UNISA.

\section{Table 3 Gender distribution of the sample}

\begin{tabular}{|c|c|c|}
\hline & Frequency & Percent \\
\hline Female & 190 & 49.4 \\
Male & 195 & 50.6 \\
Total & 385 & 100.0 \\
\hline
\end{tabular}

The use of mobile phones in all age groups has been increasing and the majority of the respondents falls in the youth category (Wang, Wu \& Wang 2009:102; Nonyongo et al. 2005:4). Ninety eight percent of the study sample falls in the youth category, which is the age 18-35. 
Students' Use of Smartphones at a Historically Disadvantaged University

Table 4 Age distribution of students

\begin{tabular}{|l|c|c|c|}
\hline & Frequency & Percent & $\begin{array}{c}\text { Cumulative } \\
\text { Percent }\end{array}$ \\
\hline$<=18$ & 25 & 6.5 & 6.5 \\
$(18-20]$ & 57 & 14.8 & 21.3 \\
$(21-23]$ & 121 & 31.4 & 52.7 \\
$(24-26]$ & 79 & 20.5 & 73.2 \\
$(27-29]$ & 55 & 14.3 & 87.5 \\
$(30-32]$ & 27 & 7.0 & 94.5 \\
$(31-33]$ & 12 & 3.1 & 97.7 \\
$(34-36]$ & 5 & 1.3 & 99.0 \\
$36<$ & 4 & 1.0 & 100.0 \\
Total & 385 & 100.0 & \\
& & & \\
\hline
\end{tabular}

Table 5 illustrates the respondents' faculties where they are registered. According to Bakon and Hassan (2012), the researchers collected data from a wide range field of study and different levels of study for investigating the perceived value of the smartphone on HE students in Malaysia. The largest percentage of respondents per faculty of the study sample indicated that $36.9 \%$ of users of mobile phones are from the Faculty of Education.

Table 5 Distribution of students by faculty

\begin{tabular}{|l|c|c|}
\hline & Frequency & Per cent \\
\hline Arts & 118 & 30.6 \\
Education & 142 & 36.9 \\
Commerce, Administration \& & 75 & 19.5 \\
Law & & \\
Science \& Agriculture & 50 & 13.0 \\
Total & 385 & 100.0 \\
\hline
\end{tabular}


The respondents were asked to indicate their degree level, shown in Table 6. The largest percentage of respondents of the study sample is $89.6 \%$, which indicated that more users of mobile phones were undergraduates. Woodcock et al. (2012:5) use an in-depth online survey in sampling different faculties for considering the smartphone learner at the university. The present study uses undergraduate and postgraduate students' interest in the use of personal technology to enhance learning. This response indicates that the study sample was dominated by undergraduates as they are the majority of students on campus.

\section{Table 6 Distribution of students by degree level}

\begin{tabular}{|l|c|c|}
\hline & Frequency & Percent \\
\hline Undergraduate & 345 & 89.6 \\
Postgraduate & 40 & 10.4 \\
Total & 385 & 100.0 \\
\hline
\end{tabular}

Table 7 indicates the current type of mobile phone students are using. The largest percentage of respondents of the study (56.88\%) indicated that there are more users of smartphones than the $43.12 \%$ who are regular cellular phone users. This result showed that the majority of students are moving towards owning a smartphone rather than a regular cellular phone. Analysing non-users and users of smartphone applications is what really drives the intention to use a smartphone app and features across users and non-users (Verkasalo et al. 2010:242). This is to be expected since the price of the product is decreasing, and a wide variety of models becoming available.

The binomial test was used to determine whether there is a significant difference between the proportion of smartphone users and regular cellular phone users (see Table 7). For the research, questions constructed and tested were as follows:

1. How has smartphone use affected students' ways of learning at an HDU?

2. To what extent do students have access to smartphones at an HDU? 
3. What smartphone capability or function enhances students' learning at an HDU?

The results for the main objective of the study in Table 7 indicate that the study sample is concentrated on smartphone users rather than regular cellular phone users. According to the associative test results on mobile phone capabilities and mobile phone type users, regular cellular phone users commented on smartphone capabilities as enhancing learning more. The ownership and use of smartphones were higher than the ownership and use of regular cellular phones.

\section{Table 7 Results on the Proportion of Smartphone and Regular Cellular Phone Users}

\begin{tabular}{|c|c|c|c|c|c|}
\hline Test Result & Category & $\mathrm{N}$ & $\begin{array}{c}\text { Observed } \\
\text { Prop. }\end{array}$ & $\begin{array}{c}\text { Test } \\
\text { Prop. }\end{array}$ & $\begin{array}{c}\text { P-value } \\
\text { (2-tailed) }\end{array}$ \\
\hline \multirow{2}{*}{ Phone Type } & Smartphone & 219 & .57 & .50 & .008 \\
& Regular Phone & 166 & .43 & & \\
& & 385 & 1.00 & & \\
\hline
\end{tabular}

The p-value of 0.008 indicates that there was a difference between the proportion of smartphone users and regular cellular phone users at the 5\% level of significance. Smartphone capabilities drive the use and owning of the smartphone that is mobile Internet (Verkasalo et al. 2010:242). The developments and improvements of the smartphone by product designers induce consumers to move towards owning one.

The main study objective was reached, and research questions were formulated and tested using the binomial test. The findings confirmed the alternative hypothesis that smartphone users surpass regular cellular phone users (Mokoena 2013). These findings confirmed that the availability of smartphones is greater than the availability of regular cellular phones.

The proportion of smartphone and regular cellular phone users was analysed. The study findings revealed that the study sample was dominated by smartphone users. Students regarded smartphones as a useful tool for their learning. Even the regular cellular phone users regarded the smartphone capabilities as useful functions for students' learning (Mokoena 2013). 


\section{Conclusion}

This paper has investigated smartphone use and ownership as a potential tool to enhance students' learning at 'Unizulu' as a poorly resourced HE environment. Most studies of this nature (Nonyongo et al. 2005; Bakon \& Hassan 2013; and El-Hussein \& Cronje 2010) have been outlined in distance learning and urban universities, but not in a rural residential university with students of a poor socio-economic background. The results indicated that there are more smartphone users than regular cellular phone users. Students have access to the right potential tool to enhance their learning at 'Unizulu'. This investigation has laid a foundation to implement mobile learning at rural residential universities inasmuch as the study results indicated that the majority of students own the right potential tool to enhance their learning.

Ally's study (2009) indicates an increase of smartphone use across different sectors of education in developed and developing countries. The supply of mobile handset devices using the Android Operating System surpasses the shipment of any kind of telecommunication technology devices in 2014 (Lunden 2014:1). This has indicated an increase in smartphone availability worldwide in developing and developed countries. Sarwar and Soomro (2013:223), in studying the impact of smartphones on society state that they are beginning to be a norm in the society: consumers are in the process of moving away from regular cellular phone use. Even in resource-poor HE in $\mathrm{SA}$, the results found that the majority of students are smartphone users rather than regular cellular phone users.

Most of the literature reviewed acknowledged that smartphone technology has the potential to enhance students' learning at university (Yu \& Conway 2012; Jones \& Edwards 2009; Nonyongo et al. 2005; M-Learning Conference 2004). At the University of Bath in England students recommend the smartphone texting service as a powerful tool that works as a reminder about work to be done, important deadlines and administrative changes on campus.

This investigation contributes to the body of knowledge for smartphone use in an $\mathrm{HE}$ environment, specifically in rural residential universities in developing countries such as South Africa. The study revealed that even in rural residential universities with students from a poor socioeconomic background, the majority of these students are smartphone users rather than regular cellular phone users. This indicates that the transition to smartphone use is growing fast even in HDUs located in developing countries 
of Africa. This indicates the potential growth of developing countries' higher education resources can be built on the foundation of technological integration in areas of rural development. The literature also provided models and theories used in understanding technology acceptance by consumers in a variety of training settings.

\section{References}

Abdulwahab, L. \& Z.M. Dahalin, 2010. A Conceptual Model of Unified Theory of Acceptance and Use of Technology (UTAUT) Modification with Management Effectiveness and Program Effectiveness in Context of Telecentre. African Scientist 11,4: 267 - 275. Available at:

https://pdfs.semanticscholar.org/7757/5eae07c4a7dc4157a38f51ad09f9b cda3b0d.pdf

Ally, M. 2009. Mobile Learning: Transforming the Delivery of Education and

Training. Edmonton, AB: AU Press, Athabasca University.

Ajzen, I. 1991. The Theory of Planned Behavior. Organizational Behavior and Human Decision Processes 50:179 - 211.

https://doi.org/10.1016/0749-5978(91)90020-T

Attewell, J. \& C. Savill-Smith 2005. Mobile Learning Anytime Everywhere: A Book of Papers From MLEARN 2004. Learning and Skills Development Agency.

Babbie, E.R. 1992. The Practice of Social Research. $6^{\text {th }}$ Edition. Belmont, CA: Wadsworth.

Bakon, K.A. \& Z. Hassan 2013. Perceived Value of Smartphone and its Impact on Deviant Behaviour: An Investigation on Higher Education Students in Malaysia. Available at SSRN 2349457.

Barker, A., G. Krull \& B. Mallinson 2005. A Proposed Theoretical Model for m-Learning Adoption in Developing Countries. In Proceedings of Mlearn. P. 4.

Bandura, A. 1986. Social Foundations of Thoughts and Action: A Social Cognitive Theory. Englewood Cliffs, NJ: Prentice-Hall.

Bell, J. 1999. Doing Your Research Project: A Guide for First Time Researchers in Education and Social Science. $3^{\text {rd }}$ Edition. St Edmundsbury Press.

Bruner, G.C. \& A. Kumar 2005. Explaining Consumer Acceptance of Handheld Internet Devices. Journal of Business Research 58,5: 553 - 558. 
https://doi.org/10.1016/j.jbusres.2003.08.002

Clough, G., A.C. Jones, P. McAndrew \& E. Scanlon 2007. Informal Learning with PDAs and Smartphones. Journal of Computer Assisted Learning 24,1: 359-371.

Caverly, D., A. Ward \& M. Caverly 2009. Techtalk: Mobile Learning and Access. Journal of Developmental Education 33,1: 38 - 39.

Davis, F.D., R.P. Bagozzi \& P.R. Warshaw 1992. Extrinsic and Intrinsic Motivation to Use Computers in the Workplace. Journal of Applied Social Psychology 22,14: 1111-1132.

https://doi.org/10.1111/j.1559-1816.1992.tb00945.x

Doocy, S., \& G. Burnham 2005. Assessment of Socio-Economic Status in the Context of Food Insecurity: Implications for Field Research. World Health \& Population 8,3: 32 - 42. https://doi.org/10.12927/whp.2006.18212

El-Hussein, M.O.M. \& J.C. Cronje 2010. Defining Mobile Learning in the Higher Education Landscape. Educational Technology \& Society 13,3: 12 $-21$.

Fishbein, M. \& I. Ajzen 1975. Belief, Attitude, Intention and Behavior: An Introduction to Theory and Research. Reading, MA: Addison.

Islam, S. \& A. Gronlund 2011. Factors Influencing the Adoption of Mobile Phones among the Farmers in Bangladesh: Theories and Practice. International Journal of Advances In ICT For Emerging Regions 04,1: 414.

Jones, G.M. \& G. Edwards 2009. Time to Engage? Texting to Support and Enhance First Year Undergraduates Learning. International Journal of Interactive Mobile Technologies 3,2: 7 - 11.

https://doi.org/10.3991/ijim.v3i2.744

Kirk, R.E. 1996. Practical Significance: A Concept whose Time has Come. Educational And Psychological Measurements Journal 56,5: 746 - 759. https://doi.org/10.1177/0013164496056005002

Krejcie, R.V. \& D.W. Morgan 1970. Determining the Sample Size for Research Activities. Educational Psychological Measurements 30,1:607 -610 .

https://doi.org/10.1177/001316447003000308

Lamb, C.W., F.H. Hair, C. McDaniel, C. Boshoff \& N.S. Terblanche 2008. Marketing. $3^{\text {rd }}$ Edition. South Africa: Oxford University Press Southern Africa. 
Students' Use of Smartphones at a Historically Disadvantaged University

Lunden, I. 2014. Gartner: 2.5B PCs, Tablets, and Mobile will be Shipped in 2014, 1.1b of Them on Android. Available at: http://techcrunch.com/2014/01/07/gartner2-5b-pcs-tablets-and-mobileswill-be-shipped-in-2014-1-1b-of-them-on-android/ (Accessed on 10 May 2014.)

Mokoena, S. 2013. Students' Use of Smartphones at a Historically Disadvantaged University. M Com., UZ, Kwadlangezwa, SA.

Nonyongo, E., K. Mabusela \& V. Monene 2005. Effectiveness of SMS Communication between University and Students. In Proceedings of the mLearn-4th World Conference on Mobile Learning. Cape Town, Africa do Sul.

Oliveira, T. \& M.F. Martins 2011. Literature Review of Information Technology Adoption Models at Firm Level. The Electronic Journal Information Systems Evaluation 14,1: 110 - 121.

Sarwar, M. \& T.R. Soomro 2013. Impacts of Smartphones on Society.

European Journal of Scientific Research 98,1: 216 - 226.

Thompson, R.L., C.A. Higgins \& J.M. Howell 1991. Personal Computing: Towards a Conceptual Model of Utilization. MIS Quarterly 15,1: 125 143.

https://doi.org/10.2307/249443

Taylor, S. \& P.A. Todd 1995. Understanding Technology Usage: A Test of Competing Models. Information Systems Research 6,2: 144 - 176. https://doi.org/10.1287/isre.6.2.144

University of Zululand 2010. Students Enrolment for the Year 2010. University of Zululand webreg.

Venkatesh, V., M.G. Morris, F.D. Davis \& G.B. Davis 2003. User Acceptance of Information Technology: Towards a Unified View. MIS Quarterly 27,3: $425-478$.

https://doi.org/10.2307/30036540

Venkatesh, V., J.Y.L. Thong \& X. Xu 2012. Consumer Acceptance and Use of Information Technology: Extending the Unified Theory of Acceptance and Use of Technology. MIS Quarterly 36,1: 157 - 178.

https://doi.org/10.2307/41410412

Verkasalo, H., C. Lopez-Nicolas, F. Molina-Castillo \& H. Bouwman 2010. Analysis of Users and Non-Users of Smartphone Applications. Journal of Telematics and Informatics 27: 242 - 255. https://doi.org/10.1016/j.tele.2009.11.001 
Wang, Y.S., M.C. Wu \& H.Y. Wang 2009. Investigating the Determinants and Age and Gender Differences in the Acceptance of M-Learning. British Journal of Educational Technology 40,1: 92 - 118. https://doi.org/10.1111/j.1467-8535.2007.00809.x

Woodcock, B., A. Middleton \& A. Nortcliffe 2012. Considering the Smartphone Learner: An Investigation into Student Interest in the Use of Personal Technology to Enhance their Learning. Student Engagement and Experience Journal 1,1: 214.

Wu, Y.L., Y.H. Tao \& P.C. Yang 2008. The Use of Unified of Acceptance and Use of Technology to Confer the Behavioural Model of 3G Telecommunication Use. Journal of Statistics and Management 11,5: 919 - 949.

Yu, F. \& A.R. Conway 2012. Mobile/ Smartphone Use in Higher Education. Proceedings of the 2012 Southwest Decision Sciences Institute. Donaghey, AR: University of Central Arkansas.

Sello Mokoena

Department of Social Sciences Education

Faculty of Education University of Zululand

South Africa

MokoenaS@unizulu.ac.za

Rembrandt Klopper Department of Communication Science

Faculty of Arts University of Zululand

South Africa rklopper@gmail.com

Sam Lubbe Milpark Business School Milpark Education South Africa sam.lubbe@gmail.com 